\title{
Neuroprotective effects of allicin on ischemia-reperfusion brain injury
}

\author{
Xiangyi Kong ${ }^{1,2, *}$, Shun Gong ${ }^{3, *}$, Lijuan $\mathrm{Su}^{4, *}$, Chen $\mathrm{Li}^{5}$ and Yanguo Kong ${ }^{1}$ \\ ${ }^{1}$ Department of Neurosurgery, Peking Union Medical College Hospital, Chinese Academy of Medical Sciences, No. 1 Shuaifuyuan \\ Hutong, Dongcheng District, Beijing, P. R. China \\ ${ }^{2}$ Department of Breast Surgical Oncology, National Cancer Center/Cancer Hospital, Chinese Academy of Medical Sciences \\ and Peking Union Medical College, Chaoyang District, Panjiayuan, Nanli 17, Beijing, P. R. China \\ ${ }^{3}$ Department of Neurosurgery, Shanghai Institute of Neurosurgery, PLA Institute of Neurosurgery, Shanghai Changzheng \\ Hospital, Second Military Medical University, Shanghai, P.R. China \\ ${ }^{4}$ College of Computer Science and Technology, Zhejiang University, Hangzhou, Zhejiang, P.R. China \\ ${ }^{5}$ Cancer Epigenetic Laboratory, Department of Clinical Oncology, State Key Laboratory of Oncology in South China, Sir YK \\ Pao Center for Cancer and Li Ka Shing Institute of Health Science, The Chinese University of Hong Kong, Shatin, Hong Kong \\ *These authors have contributed equally to this work \\ Correspondence to: Yanguo Kong, email: kong0126@126.com \\ Keywords: allicin; ischemia-reperfusion brain injury; neuroprotection; oxidative stress \\ Received: March 01, $2017 \quad$ Accepted: June 19, $2017 \quad$ Published: November 10, 2017 \\ Copyright: Kong et al. This is an open-access article distributed under the terms of the Creative Commons Attribution License 3.0 \\ (CC BY 3.0), which permits unrestricted use, distribution, and reproduction in any medium, provided the original author and source \\ are credited.
}

\section{ABSTRACT}

Background: Ischemia-reperfusion brain injury (IRBI) is an important cause for mortality and morbidity. Studies on humans and animals showed that oxidative stress (OS) plays a crucial role in ischemic stroke with or without reperfusion. Allicin is reported to be able to attenuate OS and has neuroprotective effects on rabbits' ischemia-reperfusion spinal cord injury.

Aim: To explore whether Allicin pretreatment has neuroprotective effects on IRBI in mice.

Methods and results: Transient middle cerebral artery occlusion (MCAO) was conducted to induce IRBI in mice. The mice were pretreated with either Allicin (MCAOA) or normal saline in the same volume (MCAONS). Sham-operated groups [Allicin group (SOA) and normal saline group (SONS)] were also set. Blood pressure and cerebral blood flow measurements revealed comparable hemodynamics. Via brain MRI and neuronal nuclear antigen (NeuN) immune-histochemical staining, MCAOA mice had a significantly reduced stroke size than MCAONS mice $(P<0.05, n=15)$. Allicin pretreatment could attenuate the $O S$, the activity of nicotinamide adenine dinucleotide phosphate (NADPH) oxidase, inflammation, dysfunction of mitochondrial respiratory chain, and apoptosis (all $P<0.05, n=15$ ). Furthermore, Allicin also increased the activities of endogenous antioxidant enzymes, including catalase (CAT), superoxide dismutase (SOD), glutathione peroxidase (GPX), and glutathione S-transferase (GST), and promoted the angiogenesis in the peri-infarct zone (all $P<0.05, n=15$ ).

Conclusion: We showed that Allicin could protect mice from IRBI through a series of mechanisms. Allicin represents a new therapeutic direction of IRBI. 


\section{INTRODUCTION}

Stroke is one of the most leading global causes of mortality across the world [1]. Despite ongoing advances in stroke imaging and treatment, ischemia-reperfusion brain injury (IRBI) stroke continues to debilitate patients with devastating outcomes at both personal and societal levels. Therefore, it is important to illuminate the exact molecular biological mechanisms underlying the pathogenesis of IRBI and explore more effective therapies.

Oxidative stress (OS) plays important roles in cardia-cerebrovascular diseases [2]. Many human and animal researches demonstrated a correlation between IRBI and increased systemic and local OS $[2,3]$. Targeting OS in both primary ischemic-injury and the following reperfusion-injury, lots of medicine, especially natural products extracted from medicinal plants, have been proved to have neuroprotective effects on IRBI [4].

Garlic, as a natural crop, contains rich sulfurcontaining amino acids. It has been used as important traditional Chinese medicine with little reported toxicity for centuries in China [5]. Many studies have suggested that the pharmacologic actions of garlic are associated with its biological pharmacological effects like anticancer, antihypertensive, anti-parasitic, anti-fungal, anti-microbial and anti-inflammatory activities [6-9]. In 2012, Zhu, et al.'s research revealed that Allicin could protect against ischemia-reperfusion injury of spinal cord [10]. In 2015, Zhang et al. published a study in Mol Med Rep that explored Allicin's protective effects against IRBI in rat models [11]. Rats were randomly assigned to the MCAO group, the allicin + MCAO group, and the sham-operation group. Their results demonstrated that Allicin decreased the infarction area, cerebral water content, neuron apoptosis, tumor necrosis factor (TNF- $\alpha$ ) expression, and the activities of serum myeloperoxidase (MPO). However, the intervention in their study was administering Allicin after the MCAO procedure $(50 \mathrm{mg} / \mathrm{kg}$ i.p. after 3 hours of reperfusion daily for 5 consecutive days), which could not be able to evaluate the preventive effects of Allicin on IRBI. Secondly, since the direct effects of Allicin was anti-OS theoretically instead of anti-inflammation, only exploring the serum TNF- $\alpha$ level and MPO activity seems insufficient to elucidate the specific mechanism in Allicin's protective effects. In this study, we thus more deeply analyzed the preventative and therapeutic effects of Allicin on IRBI. In concrete terms, we explored whether mice that received Allicin preoperatively could be protected from ischemia-reperfusion-induced and OSmediated brain injury and brain function impairments. Allicin's effects on mitochondrial signaling pathways which are crucially involved in OS-processes were also investigated.

\section{RESULTS}

\section{Reduced brain infarction after ischemia- reperfusion injury in MCAOA mice}

Following $24 \mathrm{~h}$ of reperfusion, both MCAOA and MCAONS mice underwent a comparable weight loss (data not shown). To quantify stroke size, mice underwent brain MRI scannings [12]. Morphometrical analysis revealed a significantly reduced stroke size in MCAOA mice compared with MCAONS mice (MCAOA: $27.33 \pm 8.33$ $\mathrm{mm}^{2}$ vs. MCAONS: $40.65 \pm 10.35 \mathrm{~mm}^{2} ;{ }^{*} \mathrm{p}<0.05 ; \mathrm{n}=$ 15; Figure 1). SOA and SONS mice did not display any lesions (data not shown).

\section{Allicin improves neurological function following MCAO}

\section{Neurological severity score (NSS)}

Figure 2A shows the median NSS with percentiles (5\% to $95 \%$ ) for each group at 4 time-points. Sham-operated mice did not exhibit any neurological deficits (data not shown). In contrast, after 1 hour of MCAO, both MCAONS and MCAOA mice exhibited marked coordination dysfunction, whose median NSS scores were 14 and 13 respectively. Although the MCAOA mice had a trend toward better neurological functions (lower median NSS), the difference was not significant (MCAONS $13.60 \pm 1.02$ vs. MCAOA $\left.12.73 \pm 1.28 ;{ }^{*} \mathrm{p}=0.058>0.05 ; \mathrm{n}=15\right)$. In the following course, significant functional improvement was observed in MCAOA group. The NSS decreased to a median score of 13 in MCAONS group and 11 in MCAOA group after 24 hours of reperfusion (MCAONS $13.40 \pm 1.31 \mathrm{vs.} \mathrm{MCAOA} 11.60 \pm$ $\left.1.54 ;{ }^{*} \mathrm{p}=0.002<0.05 ; \mathrm{n}=15\right)$, and gradually decreased to 9 and 7 respectively at 7 days eventually ( 3 days: MCAONS $12.00 \pm 1.93$ vs. MCAOA $9.93 \pm 1.91 ;{ }^{*} \mathrm{p}=0.008<0.05 ; 7$ days: MCAONS $9.13 \pm 1.63$ vs. MCAOA $7.40 \pm 2.36 ;{ }^{*} \mathrm{p}=$ $0.032<0.05 ; \mathrm{n}=15$ ), suggesting that Allicin pretreatment had neurotrophic effects on IRBI.

\section{Bederson-based four-point scale test}

After $1 \mathrm{~h}$ of reperfusion, both MCAONS and MCAOA mice exhibited marked coordination dysfunctions, manifesting as decreased activity, imbalance of movement, and decreased gripping ability (MCAONS: $1.80 \pm 0.54$ vs. MCAOA: $1.73 \pm 0.44 ; \mathrm{P}=0.1014 ; \mathrm{n}=$ 15 ; Figure 2B). After $24 \mathrm{~h}$ of reperfusion, MCAOA mice showed an improved neurological function compared with MCAONS mice (MCAONS: $1.47 \pm 0.49$ vs. MCAOA: $1.13 \pm 0.34 ;{ }^{*} \mathrm{P}=0.0004 ; \mathrm{n}=15$; Figure $2 \mathrm{~B}$ ). Moreover, neurological deficit score of MCAOA was improved at 24 $\mathrm{h}$ compared with $1 \mathrm{~h}$ of reperfusion $(24 \mathrm{~h}: 1.13 \pm 0.34 \mathrm{vs}$. $1 \mathrm{~h}: 1.73 \pm 0.44 ;{ }^{*} \mathrm{P}=0.0448<0.05 ; \mathrm{n}=15$; Figure 2B). Such improvement was not observed in MCAONS mice ( 24 h: $1.47 \pm 0.49$ vs. 1 h: $1.80 \pm 0.54 ; \mathrm{P}=0.7239 ; \mathrm{n}=15$; 
Figure 2B), suggesting an improved recovery potential in MCAOA mice. Both SONS and SOA mice did not exhibit any neurological deficit at 1 or $24 \mathrm{~h}$ (data not shown).

\section{Comparable cerebral perfusion and systemic blood pressure in MCAONS and MCAOA mice}

Basal regional cerebral blood flow (rCBF) was comparable between MCAONS and MCAOA mice. Following the ligation of the common carotid artery (CCA), a comparable reduction in blood flow was observed in both MCAO groups (MCAONS: $-52.1 \pm 8.69 \%$ vs. MCAOA: $-50.4 \pm 7.38 \%$; Figure 3A). Similarly, after the insertion of the silicon thread, a comparable rCBF reduction was recorded in MCAONS and MCAOA mice (MCAONS: $-81.82 \pm 7.49 \%$ vs. MCAOA: $-85.13 \pm 6.91 \%$; Figure $3 \mathrm{~A}$ ). After the retraction of the silicone thread, a comparable re-establishment of blood flow was observed in MCAONS and MCAOA mice (MCAONS: $45.58 \pm 13.12 \%$ vs. MCAOA: $47.41 \pm 11.11 \%$; $\mathrm{p}=\mathrm{NS}$ for all time points; $\mathrm{n}=15$; Figure $3 \mathrm{~A}$ ). No differences in systolic blood pressure (SBP) and diastolic blood pressure (DBP) as well as in heart rate were observed in both MCAONS and MCAOA groups (SBP: MCAONS: $156.7 \pm 15.67 \mathrm{mmHg}$ vs. MCAOA: $160.7 \pm 14.24 \mathrm{mmHg} ; \mathrm{p}=\mathrm{NS} ; \mathrm{n}=15$; Figure 3B; DBP: MCAONS: $131 \pm 16.05 \mathrm{mmHg}$ vs. MCAOA: $126.7 \pm 13.21 \mathrm{mmHg} ; \mathrm{p}=\mathrm{NS} ; \mathrm{n}=15$; Figure $3 \mathrm{C}$; Heart rate: MCAONS: 510.3+23.03 b.p.m. vs. MCAOA: $520.7 \pm 17.88$ b.p.m.; $\mathrm{p}=\mathrm{NS} ; \mathrm{n}=15$; Figure 3D).

\section{Lower IRBI-induced systemic OS in MCAOA mice}

No significant difference of superoxide anion free radical (SAFR) and MDA were detected between SONS

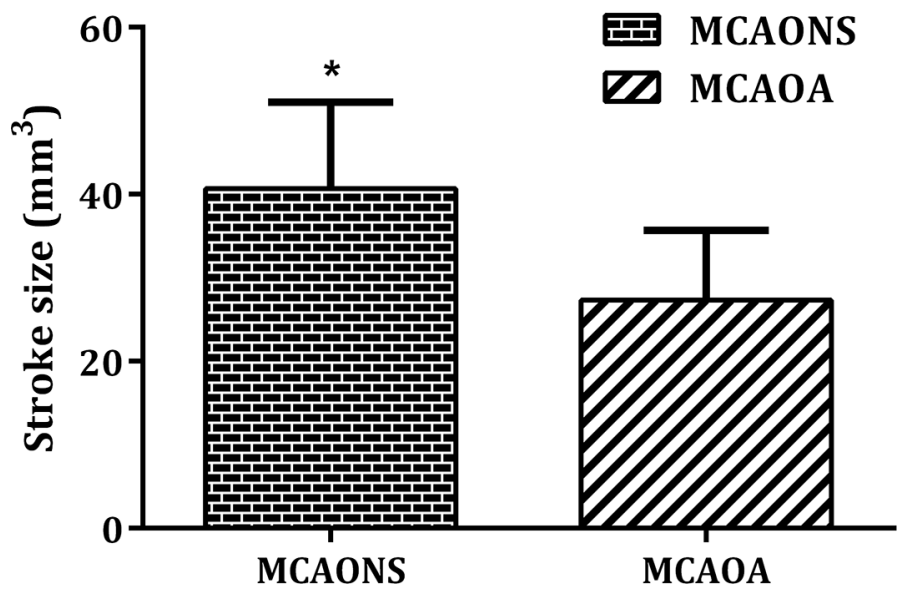

Figure 1: Stroke size measurement after ischemia-reperfusion brain injury through brain MRI (T2WI) $24 \mathrm{~h}$ after MCAO in MCAONS mice and MCAOA mice. MCAOA mice show reduced stroke size compared with MCAONS mice, ${ }^{*} \mathrm{P}<0.05$. Values are given as cubic millimeter.

A

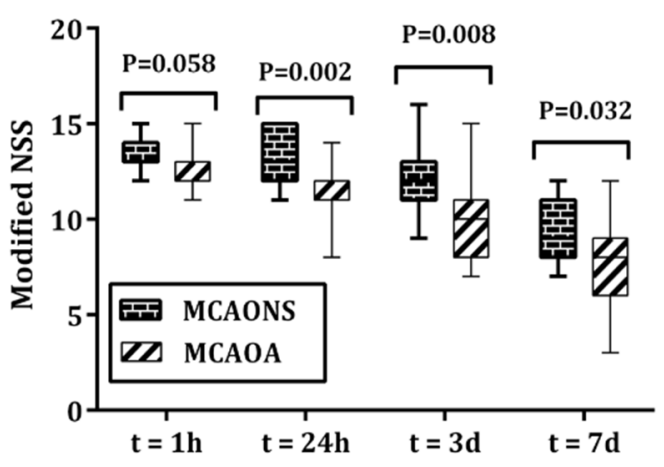

B

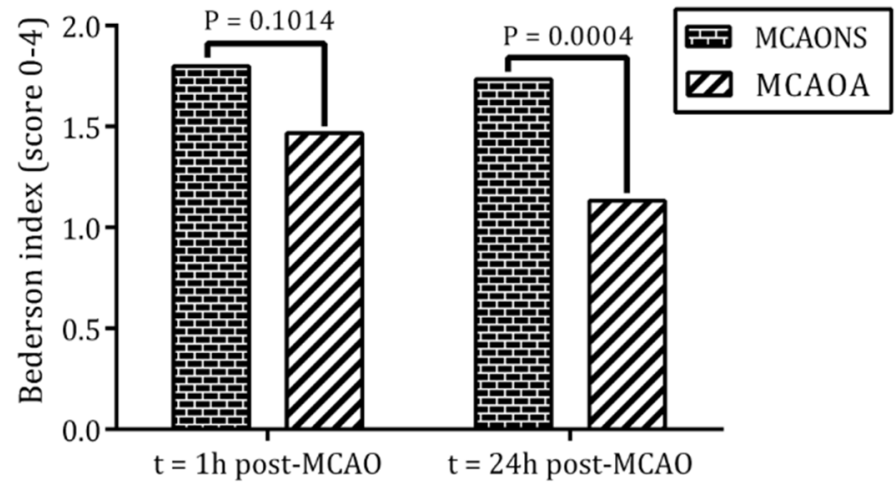

Figure 2: The neurological severity scores (NSS) (A) for MCAONS mice and MCAOA mice at $1 \mathrm{~h}, 24 \mathrm{~h}, 3 \mathrm{~d}$ and $7 \mathrm{~d}$ after MCAO, and Bederson test (B) for MCAONS mice and MCAOA mice at $1 \mathrm{~h}, 24 \mathrm{~h}$ after MCAO. ${ }^{*} \mathrm{P}<0.05$. 
group and SOA group (SAFR: MCAOA 275.62 \pm 20.08 vs. MCAONS $284.86 \pm 23.05 \mathrm{ng} / \mathrm{L} ; \mathrm{p}=0.2673 ; \mathrm{n}=15$; Figure 4A; MDA: MCAOA: $2.30 \pm 0.15$ vs MCAONS: $2.22 \pm 0.17$ $\mathrm{nmol} / \mathrm{L} ; \mathrm{p}=0.1997 ; \mathrm{n}=15$; Figure 4B). Although SAFR and MDA levels in MCAONS and MCAON groups both increased after $1 \mathrm{~h}$ of reperfusion, the MCAOA mice showed a lower OS degree than MCAONS mice (SAFR: MCAOA $416.15 \pm 20.41$ vs. MCAONS $453.66 \pm 19.17 \mathrm{ng} / \mathrm{L} ;{ }^{*} \mathrm{p}<$ $0.05 ; \mathrm{n}=15$; Figure 4A; MDA: MCAOA: $3.06 \pm 0.17$ vs MCAONS: $3.37 \pm 0.17 \mathrm{nmol} / \mathrm{L} ;{ }^{*} \mathrm{p}<0.05 ; \mathrm{n}=15$; Figure 4B). After $24 \mathrm{~h}$ of reperfusion, SAFR and MDA followed the similar comparison trend (SAFR: MCAOA 335.48 \pm 17.70 vs. MCAONS $366.41 \pm 15.53 \mathrm{ng} / \mathrm{L} ;{ }^{*} \mathrm{p}<0.05 ; \mathrm{n}=15$; Figure 4A; MDA: MCAOA $2.61 \pm 0.16$ vs. MCAONS: $2.91 \pm 0.27$ $\mathrm{nmol} / \mathrm{L} ;{ }^{*} \mathrm{p}<0.05 ; \mathrm{n}=15$; Figure 4B).

\section{Neuroprotection, OS, inflammation and microvessel density by immunohistochemistry}

The number of mature NeuN-immunoreactive neurons was higher in the MCAOA group than in MCAONS group (MCAONS $120.0 \pm 4.615$ vs. MCAOA $132.0 \pm 2.493 ;{ }^{*} \mathrm{p}=$ $0.0308<0.05 ; \mathrm{n}=15$; Figure $5 \mathrm{~A}-5 \mathrm{C}$ ) after $24 \mathrm{~h}$ of reperfusion. There were more 8-hydroxy-2'-deoxyguanosine (8-OHdG)positive cells and TNF- $\alpha$-positive cells in the peri-infarct zone in MCAONS group than in MCAOA (8-OHdG: MCAONS $31.44 \pm 1.499$ vs. MCAOA $26.51 \pm 1.154 ;{ }^{*} \mathrm{p}=0.0144<$ $0.05 ; \mathrm{n}=15$; Figure 5D-5F; TNF- $\alpha$ : MCAONS $143.2 \pm$ 5.125 vs. MCAOA $122.5 \pm 5.172 ;{ }^{*} \mathrm{p}=0.0082<0.05 ; \mathrm{n}$ $=15$; Figure $5 \mathrm{G}-5 \mathrm{I}$ ), suggesting the OS and inflammation could be attenuated by Allicin pretreatment. There were more CD34-positive cells in the cortical peri-infarct zones of the MCAOA group than in those of the MCAONS group after $24 \mathrm{~h}$ of reperfusion (MCAONS $87.17 \pm 5.365$ vs. MCAOA $115.9 \pm 4.062 ;{ }^{*} \mathrm{p}=0.0002<0.05 ; \mathrm{n}=15$; Figure 5J-5L).

\section{Cell apoptosis assessed by immunohistochemistry}

The apoptosis level and the 2 apoptosis-related proteins' expressions were measured to confirm whether Allicin could decrease cell apoptosis. Immunohistochemical stainings for the anti-apoptotic protein $\mathrm{Bcl}-2$, and the pro-apoptotic protein Bax were conducted after $24 \mathrm{~h}$ of reperfusion $[13,14]$. The results demonstrated that the Bax expression level was much higher in the MCAONS group than in the MCAOA group (MCAONS $54.37 \pm$ 2.166 vs. MCAOA $44.47 \pm 1.891 ;{ }^{*} \mathrm{p}=0.0018<0.05 ; \mathrm{n}=$ 15; Figure 6A-6C). In contrast, the Bcl-2 expression was significantly higher in MCAOA mice than in MCAONS

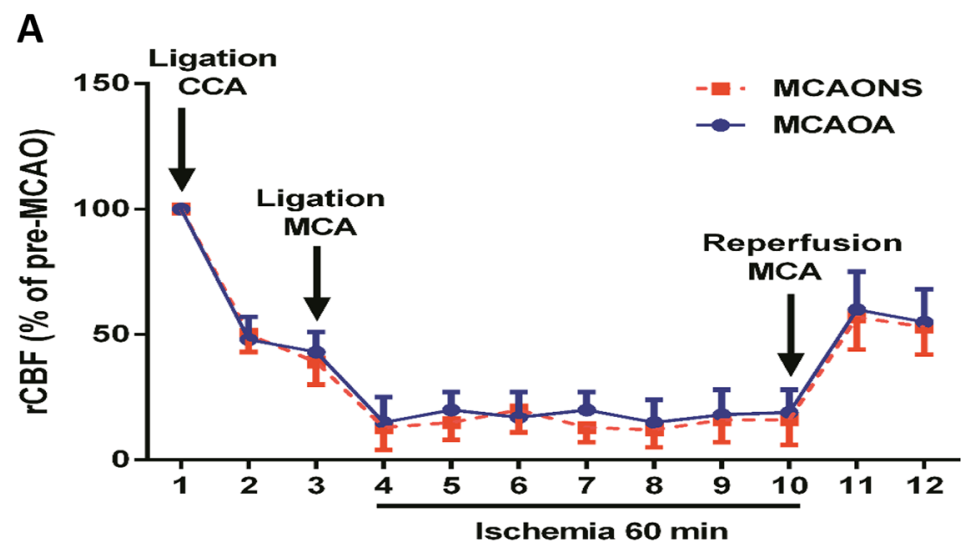

B

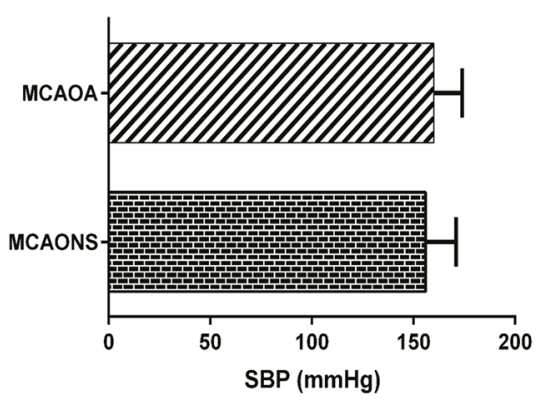

C

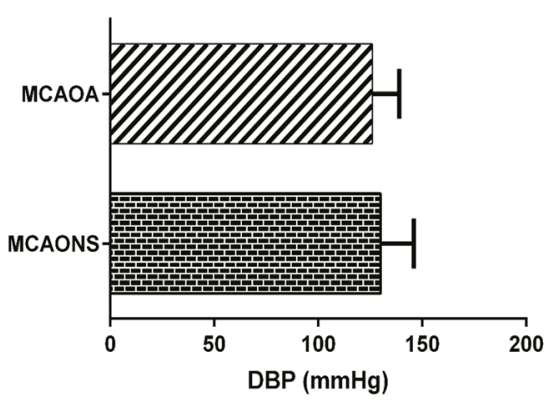

D

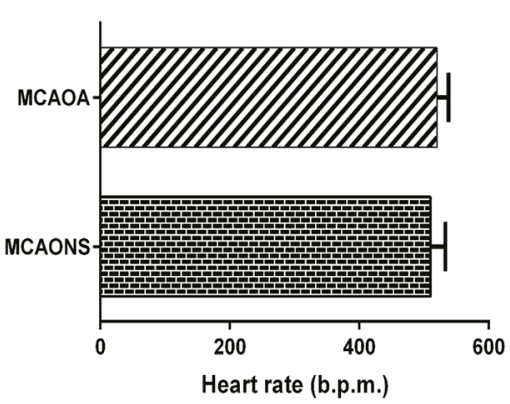

Figure 3: Cerebral blood flow and arterial blood pressure measurements. Laser Doppler measurements revealed no difference in regional cerebral blood flow before MCAO between MCAONS and MCAOA mice and showed a similar alteration upon middle cerebral artery occlusion and reperfusion ( $\mathrm{p}=\mathrm{NS} ; \mathrm{n}=15 ;(\mathbf{A})$. MCAONS and MCAOA mice do not differ in systolic blood pressure (SBP; $\mathrm{p}=\mathrm{NS}$; $\mathrm{n}=15 ;(\mathbf{B})$ and diastolic blood pressure (DBP; $\mathrm{p}=\mathrm{NS} ; \mathrm{n}=15 ;(\mathbf{C})$ as well as in heart rate $(\mathrm{p}=\mathrm{NS} ; \mathrm{n}=15 ;$ (D)). 
mice (MCAONS $40.79 \pm 2.093$ vs. MCAOA $50.91 \pm 2.137$; ${ }^{*} \mathrm{p}=0.0021<0.05 ; \mathrm{n}=15$; Figure 6D-6F).

\section{Allicin attenuated antioxidant-enzyme consumption and mitochondrial dysfunction}

The activities of GST, GPX, SOD and CAT in ipsilateral brain homogenate were measured. The results revealed that IRBI could decrease the activities of GST, GPX, SOD and CAT markedly. Compared with MCAONS group, however, Allicin treatment (MCAOA) significantly attenuated the decrease of the activities of CAT ( ${ }^{*} \mathrm{p}<0.05 ; \mathrm{n}=15$; Figure 7 A), SOD ( ${ }^{*} \mathrm{p}<0.05 ; \mathrm{n}=15$; Figure 7B), GPX ( ${ }^{*} \mathrm{p}<0.05 ; \mathrm{n}=$ 15 ; Figure $7 \mathrm{C})$ and GST $\left({ }^{*} \mathrm{p}<0.05 ; \mathrm{n}=15\right.$; Figure $\left.7 \mathrm{D}\right)$.

As compared with MCAONS mice, despite minimal effects of Allicin on the complex I and II after $1 \mathrm{~h}$ of reperfusion $(\mathrm{p}=\mathrm{NS}, \mathrm{n}=15$; Figure $8 \mathrm{~A}-8 \mathrm{~B})$, complex III and IV showed significant increment in their activities in brain tissues from MCAOA mice $\left({ }^{*} \mathrm{p}<0.05 ; \mathrm{n}=15\right.$; Figure $8 \mathrm{C}-8 \mathrm{D})$. After $24 \mathrm{~h}$ of reperfusion, MCAOA mice showed a remarkable augmentation of the mitochondrial electron transport chain (ETC) activities on all the four complexes $\left({ }^{*} \mathrm{p}<0.05 ; \mathrm{n}=15\right.$; Figure 8A-8D). We also measured the production of mitochondrial cytochrome c release to determine the effect of preserved ETC activity on SAFR release. Mitochondrial cytochrome c production showed significant increment in its activities in injured brain from Allicin pretreated mice $\left({ }^{*} \mathrm{p}<0.05 ; \mathrm{n}=15\right.$; Figure $\left.8 \mathrm{~F}\right)$.

\section{Lower gp91phox and cytochrome $\mathrm{c}$ in MCAOA mice}

Gp91phox expression was significantly increased in the brains of MCAONS mice compared with that of SONS mice (MCAONS: $255.18 \pm 25.88 \%$ vs. SONS: $100 \%$; ${ }^{*} \mathrm{P}$ $<0.05 ; \mathrm{n}=15$; Figure 8E). Interestingly, this increase was not observed in the brain of MCAOA mice compared with that of SOA ones (MCAOA: $165.64 \pm 50.10 \%$ vs. SOA: $100.63 \pm 14.63 \% ; \mathrm{P}=0.873>0.05 ; \mathrm{n}=15$; Figure
8E). In agreement with suppression of reactive oxygen species (ROS) production and the activity of gp91phox, Allicin significantly inhibited the release of mitochondrial cytochrome c $\left({ }^{*} \mathrm{P}<0.05 ; \mathrm{n}=15\right.$; Figure $\left.8 \mathrm{~F}\right)$.

\section{DISCUSSION}

Allicin, as one of garlic's active ingredients, possesses many medicinal functions, including anti-oxidant and antiinflammatory activities. The number of literatures related to garlic or Allicin increases with years (Figure 9), most of which are from North America, Europe, East Asia and South Asia (Figure 10). Studies have shown that Allicin could protect against myocardial fibrosis, myocardial hypertrophy [15], and memory and learning impairments [16] through inhibiting OS-dependent signaling pathways, increasing SOD activities and reducing MDA levels. Using spinal cord ischemia reperfusion challenged rabbits, Zhu et al. found that 2 weeks' $50 \mathrm{mg} / \mathrm{kg}$ Allicin pre-treatment reduced the infarction volumes significantly, increased motor-neuron number, and improved neurologic functions [10].

Though lots of medications with anti-oxidant activities have been shown to be able to protect against ischemia-reperfusion injury, Allicin has unique advantages. From a 50-g garlic, nearly $100 \mathrm{mg}$ Allicin can be yielded [17]. Even in energy-deficient environments, Allicin, as a kind of small lipophilic molecule, can easily cross the blood-brain barrier to immediately interact with other biologically active compounds to form many beneficial metabolites [18]. In 2015, Zhang et al. published a study in Mol Med Rep that explored the protective effects of Allicin against ischemic stroke in a rat model of MCAO [11]. Rats were randomly assigned to the MCAO group, the allicin + MCAO group, and the sham-operation group. Their results demonstrated that Allicin decreased the infarction area, cerebral water content, neuron apoptosis, tumor necrosis factor (TNF- $\alpha$ ) expression, and the activities of serum myeloperoxidase (MPO). However, the intervention in their study was administering Allicin
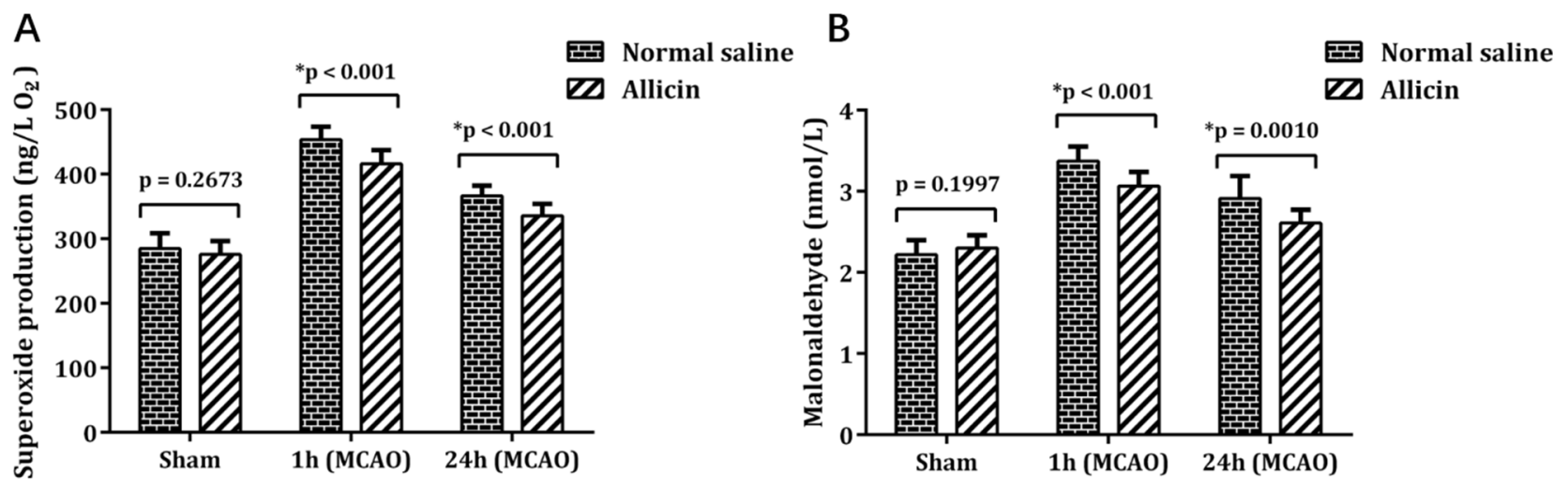

Figure 4: SAFR (A) and MDA (B) levels measured in whole blood using double antibody sandwich-Elisa method $1 \mathrm{~h}$ and $24 \mathrm{~h}$ after reperfusion. ${ }^{*} \mathrm{P}<0.05$. 
after the MCAO procedure (at a dose of $50 \mathrm{mg} / \mathrm{kg}$ i.p. 3 $\mathrm{h}$ after reperfusion daily for 5 consecutive days), which could not evaluate the preventive effects of Allicin on IRBI. Secondly, since the direct effects of Allicin was anti-OS theoretically instead of anti-inflammation, only exploring the serum TNF- $\alpha$ level and MPO activity seems insufficient to elucidate the specific mechanism in Allicin's protective effects. In the present study, we thus more deeply analyzed the preventative and therapeutic effects of Allicin on IRBI. This effect is paralleled by a reduced production of free radicals and inflammatory factors, an attenuated apoptosis and NADPH oxidase
A

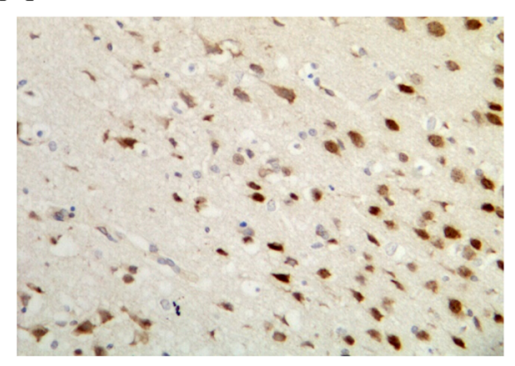

D

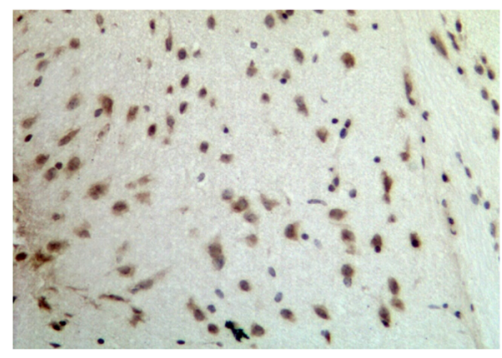

G

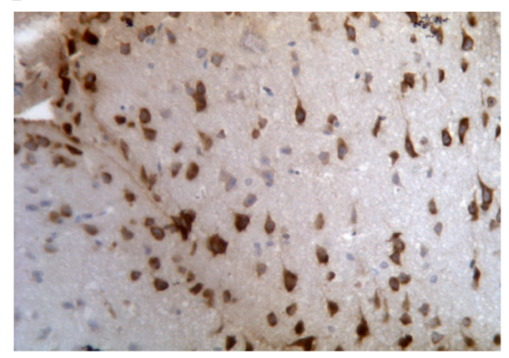

J

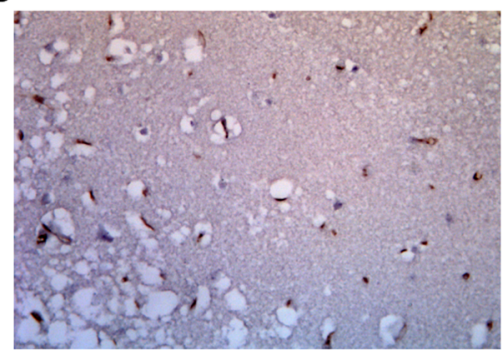

B

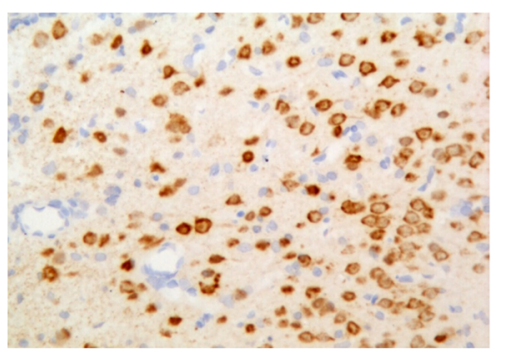

E

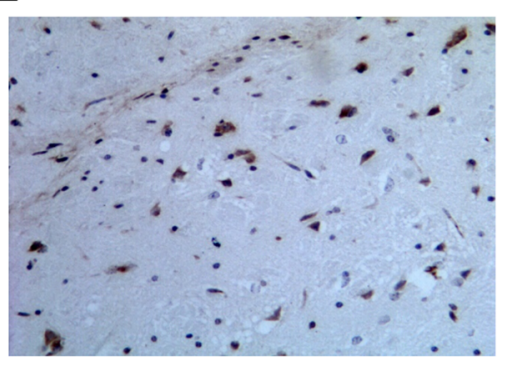

H

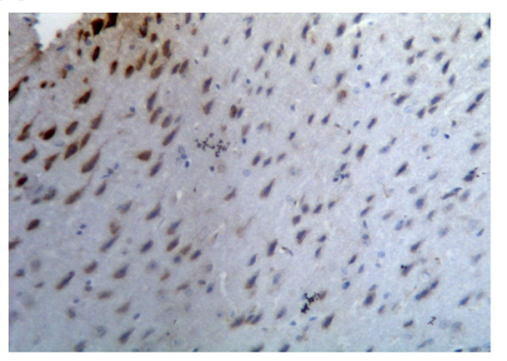

K

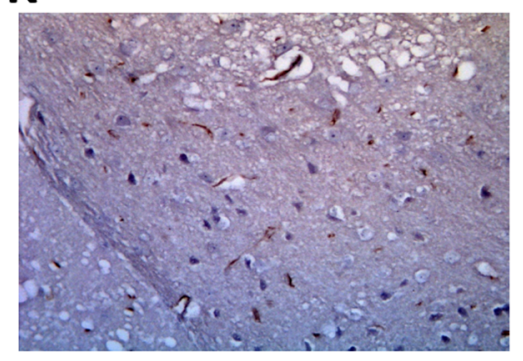

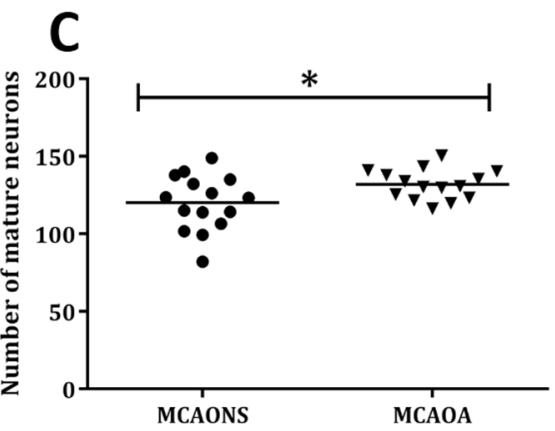
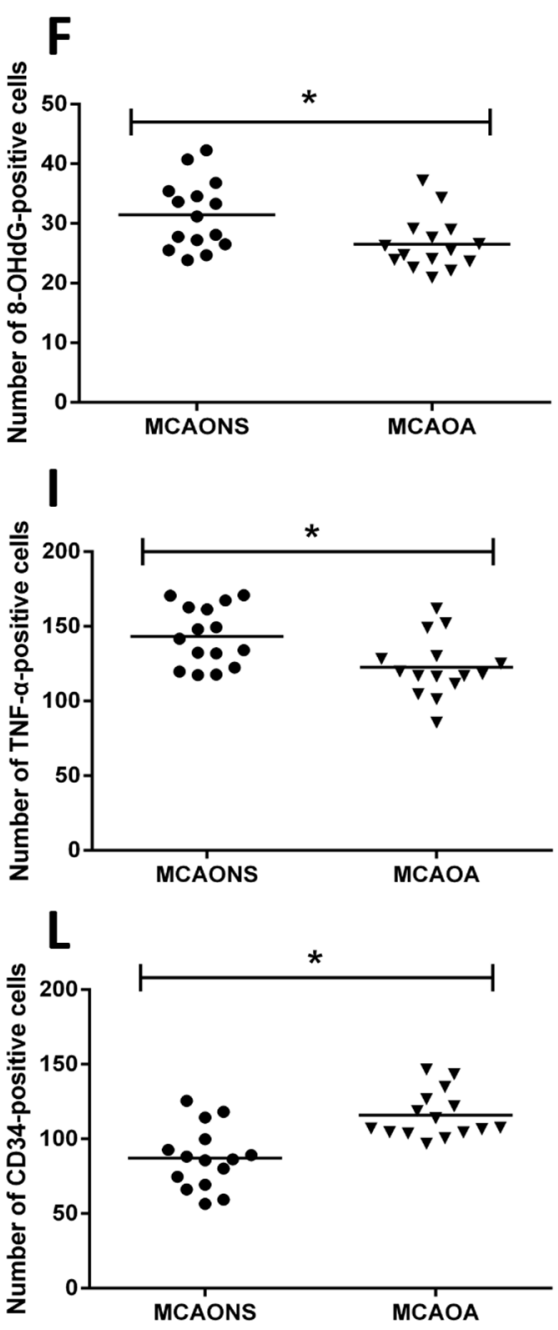

Figure 5: The number of mature NeuN-immunoreactive neurons was smaller in the MCAONS group (A) than in MCAOA group (B) ( ${ }^{*} \mathbf{p}<\mathbf{0 . 0 5} ; \mathrm{n}=15 ;$ (C) $24 \mathrm{~h}$ after reperfusion. There were considerably more 8-OHdG-positive cells cells in the peri-infarct zone in MCAONS (D) group than in MCAOA (E) $\left({ }^{*} \mathrm{p}<0.05 ; \mathrm{n}=15\right.$; (F). TNF- $\alpha$ followed the same pattern with 8-OHdG (G-I). And the number of CD34-immunoreactive cells was smaller in the MCAONS group (J) than in MCAOA group (K) $\left({ }^{*} \mathrm{p}<0.05 ; \mathrm{n}=15 ;(\mathbf{L})\right.$. 
production, increased activities of anti-oxidant enzymes, including GST, GPX, SOD and CAT, preserved functions of mitochondria respiratory chain complexes, and attenuated ROS production and mitochondrial cytochrome c release.

Transient MCAO is a well-established model of stroke [19]. In the present study, this model induced sizeable strokes and neurological deficits. Encouragingly, Allicin administration protected mice from ischemia-reperfusioninduced brain injury. After $1 \mathrm{~h}$ and $24 \mathrm{~h}$ of reperfusion, MCAOA displayed an approximately 50\% reduction of stroke volume in brain MRI examination compared with MCAONS mice. The results of immunostaining of NeuN showed there were more neurons in MCAOA mice than in MCAONS mice, suggesting that more cells survived in the peri-infarct zones of the mice pretreated with Allicin. These results expand a previously reported study that showed Allicin administration could protect against ischemiareperfusion injured spinal cord to brain. Valuation of the neurological impairment after $1 \mathrm{~h}$ of reperfusion displayed a similar degree in both MCAOA and MCAONS mice. Nevertheless, after $24 \mathrm{~h}$ of reperfusion, MCAOA mice displayed better neurological functions than MCAONS mice. Similarly, using Bederson test, assessment of neurological deficit $1 \mathrm{~h}$ after MCAO denoted a similar degree of impairment in both MCAONS and MCAOA mice. However, following $24 \mathrm{~h}$ of reperfusion, MCAOA mice displayed a marked improvement in neuromotor function compared with MCAONS mice. This indicates that the protective effects of allicin lead to a better neurological recovery after brain reperfusion. Haemodynamic values including $\mathrm{rCBF}$, heart rate and blood pressure were comparable in MCAOA and MCAONS mice, thereby excluding the impact of possible different injury degrees. Our findings have important clinical significance of translational medicine, because IRBIs are very common complications in ischemic-stroke patients receiving thrombolysis treatments [20].

Increased OS level is widely considered as a key mediator of IRBI-induced brain injury [2]. 8-OHdG is a recognized marker of DNA OS damage [21], and MDA is a biomarker for lipid peroxidation [22, 23]. Herein, we report that MCAONS mice displayed an increased SAFR and MDA production in brain tissues compared with SONS mice, demonstrating that ischemia-reperfusion injury indeed results in OS. Interestingly, brain tissue of MCAOA mice displayed much lower levels of SAFR, 8-OHdG and MDA production compared with MCAONS mice, suggesting that Allicin administration is importantly involved in the pathophysiological process. Considering the important role played by OS in IRBI, strategies aimed at preventing OS increase in this process are being sought for in recent
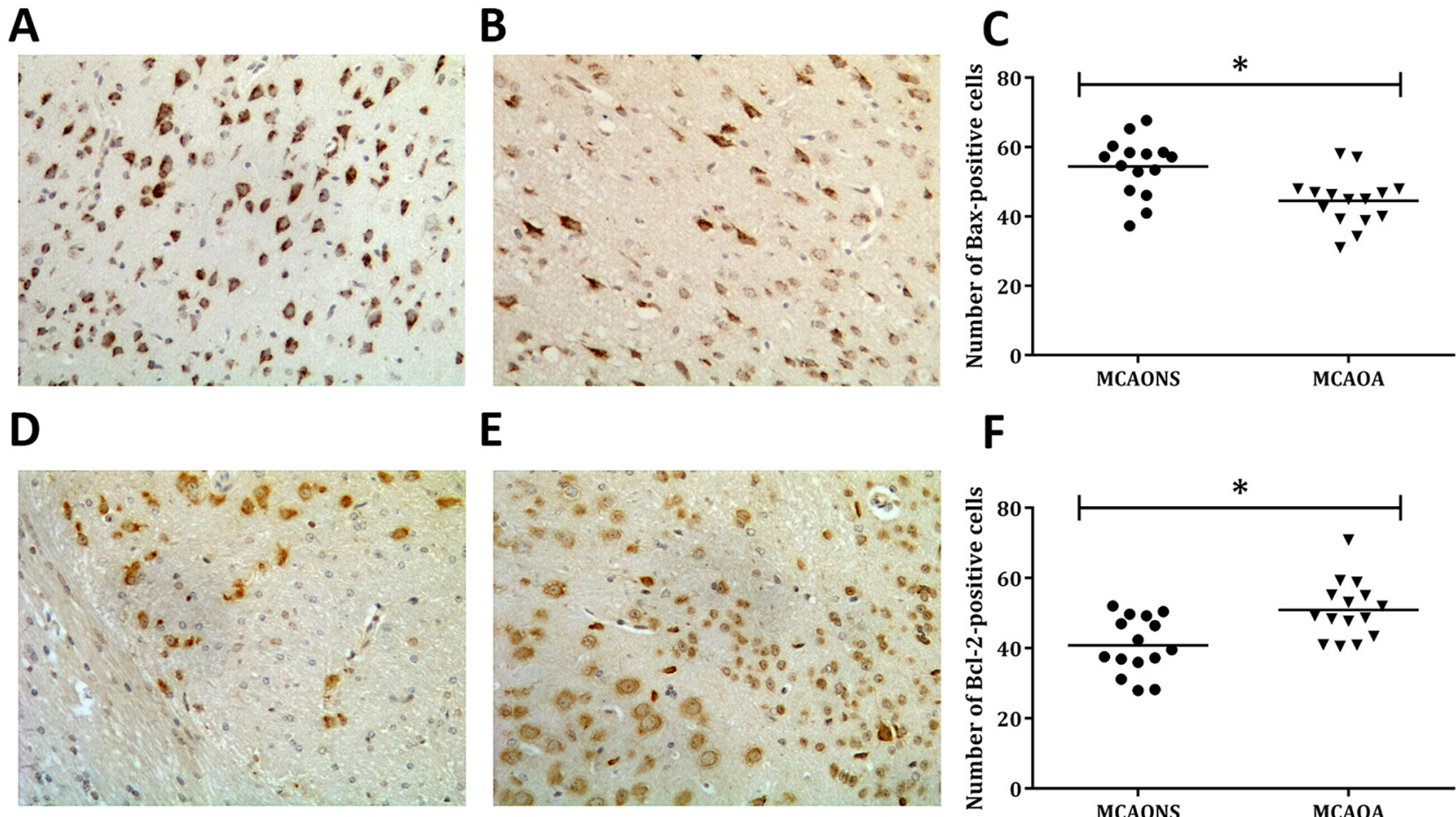

E

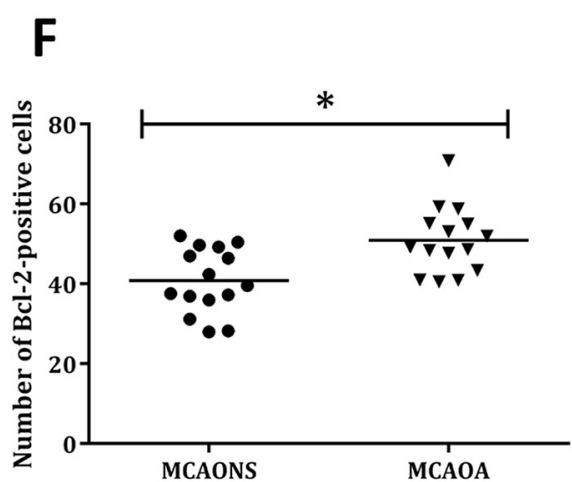

Figure 6: Cell apoptosis in the ischemic boundary zone shown by immunohistochemistry 24 h after MCAO. Immunostaining of the proapoptotic protein Bax-positive cells in MCAONS group (A) and MCAOA group (B). Allicin administration reduced the expression of $\mathrm{Bax}\left({ }^{*} \mathrm{P}<0.05 ; \mathrm{n}=15 ; \mathbf{( C )}\right.$. Immunostaining of Bcl-2 positive cells in MCAONS group (D) and MCAOA group (E). The expression of Bcl-2 in MCAOA mice was significantly higher compared to MCAONS group $\left({ }^{*} \mathrm{P}<0.05 ; \mathrm{n}=15 ;(\mathbf{F})\right.$. 
years [24, 25]. Following ischemia, increased SAFR production promotes endothelial activations and increases brain arteries' permeability, causing the expressions of pro-inflammatory cytokines such as TNF- $\alpha$, which is an important mechanism involved in stroke size $[25,26]$. During inflammation, Inflammatory cells and cytokines play important roles in the process of inflammation. Inflammation-associated cytokines include antiinflammatory and pro-inflammatory cytokines depending on their abilities to repress or increase inflammations. Key pro-inflammatory cytokines such as TNF- $\alpha$ play pivotal roles in the initiation of inflammatory-reactions and leading to expressions of other cytokines after IRBI. Our results demonstrated that Allicin significantly decreased TNF- $\alpha$ expressions, suggesting that Allicin could protect the brain from IRBI through certain anti-inflammation pathways. Additionally, we also found that levels of SAFR and MDA in peripheral blood of MCAONS mice are much higher than those of MCAOA mice, indicating systemic ROS pathway activations under these conditions.

CD34 is a recognized biomarker for the density of micro-vessels [27]. The results of immunostaining of CD34 showed there to be more CD-34-positive cells and

A

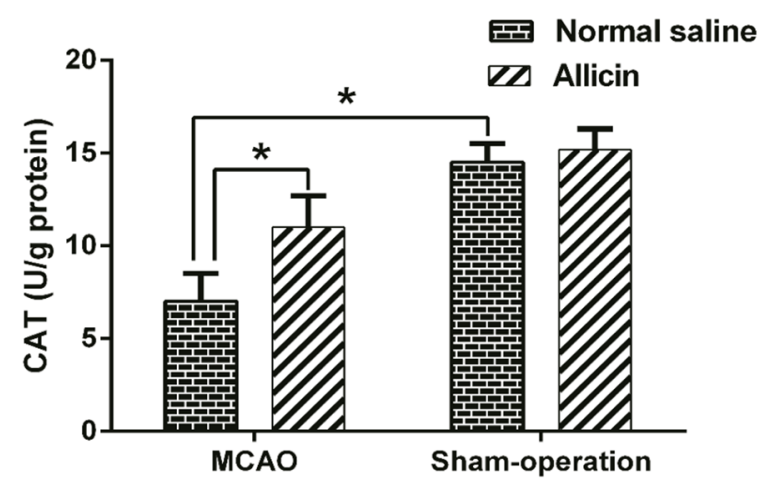

C

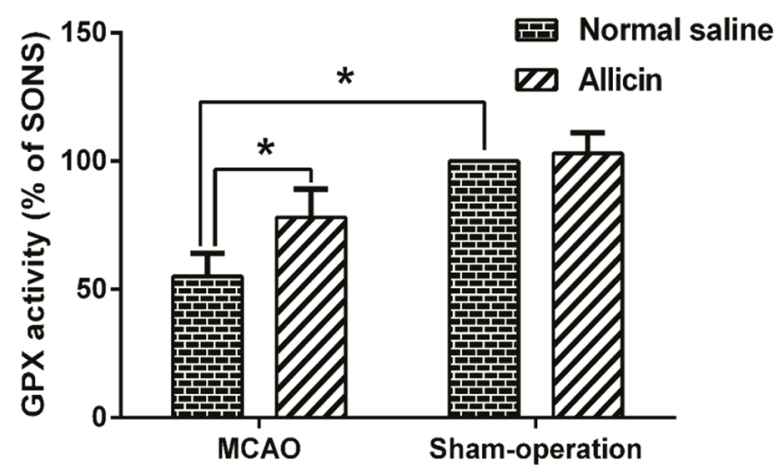

capillaries in the periinfarct zone in MCAOA mice than in MCAONS mice, suggesting Allicin could improve the blood perfusion by inducing neoangiogenesis and promoting the survival endothelial cells. We also explored the apoptosis degree in peri-infarct zones via bax, and bcl2 staining. We hypothesize that Allicin's anti-apoptosis effects are associated with its down-regulating proapoptotic proteins (Bax) and up-regulating anti-apoptotic proteins (Bcl-2).

Endogenous anti-oxidant enzymes are closely involved in many OS-related disorders like motor neuron disease and stroke [28]. GST, GPX, SOD and CAT can act together to form an OS-defense network. GST can reduce lipid hydroperoxides and free hydrogen peroxides to water, GPX functions as a selenium-dependent GPX, SOD can catalyze dismutations of superoxide to hydrogen peroxides, and CAT can catalyze the transformation of $\mathrm{H}_{2} \mathrm{O}_{2}$ to water [29]. According to our findings, Allicin pretreatment markedly imporved the activities of GST, GPX, SOD, and CAT in MCAOA mice brain, reflecting the roles Allicin played in enhancing activities of antioxidant enzymes. These enzymes protect against IRBI via limiting OS-mediated injuries, as well as forming a second

\section{B}

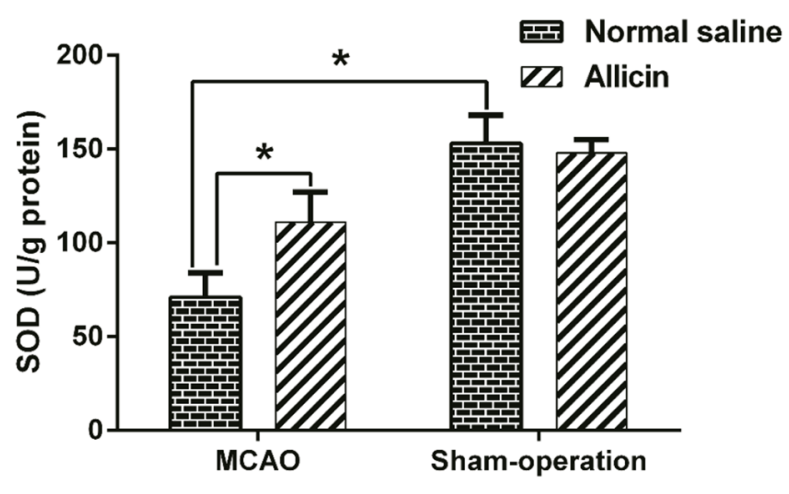

D

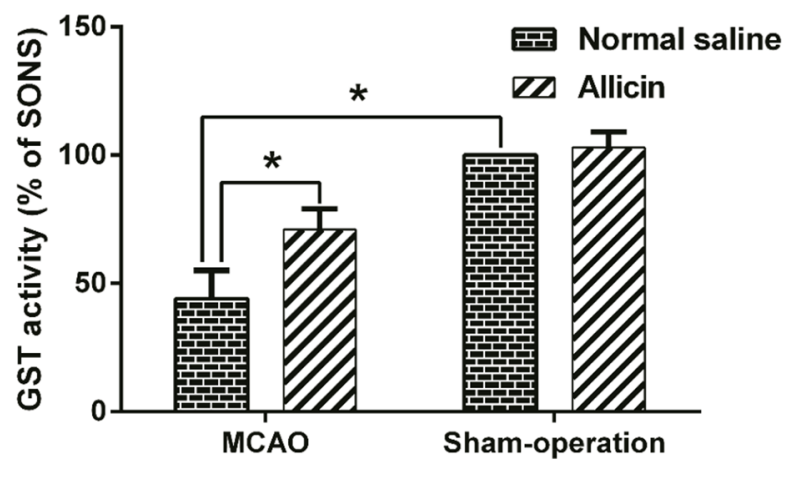

Figure 7: Allicin upregulated the activities of CAT, SOD, GPX and GST in MCAO injured brain. After pretreatment with Allicin $(50 \mathrm{mg} / \mathrm{kg}$ ) for two weeks, mice were exposed to MCAO operation and sacrificed $24 \mathrm{~h}$ after reperfusion. The activities of CAT (A), SOD (B), GXP (C) and GST (D) in brain were detected. The data was represented as means \pm standard error of the mean (S.E.M.). " $\mathrm{p}<0.05$. 
defense line by activating down-stream metabolizing enzymes, like NQQ1 and HO-1 [29]. These data fully revealed Allicin's vital function in upregulating antioxidant enzymes' activities.

Mitochondria plays pivotal roles in producing adenosine triphosphate (ATP) and regulating cellular metabolisms via mitochondrial respiratory chain complexes. Thus, energy failure induced by mitochondria dysfunction is a significant factor in various disorders, including IRBI [30]. Studies showed that during OS conditions, the activities of complex I-IV of mitochondria decreased significantly [30, 31]. In our study, Allicin administration protected the functions of mitochondria respiratory chain complexes following MCAO. Further, Allicin attenuated the release of mitochondrial cytochrome c. The increase of cytochrome $\mathrm{c}$ is a major detrimental factor that activates multiple downstream signaling pathways in ischemic conditions to execute cell death.

NADPH oxidase is a membrane-bound enzyme. It is widely expressed in cerebral arteries and considered as an important source of ROS productions in cardiacerebrovascular diseases [32]. NADPH oxidase expressions are known to increase in disease conditions such as ischemia [33], and its genetic knockout in mice could reduce brain infarction [34]. In line with these previous findings, although the expressions of gp91phox
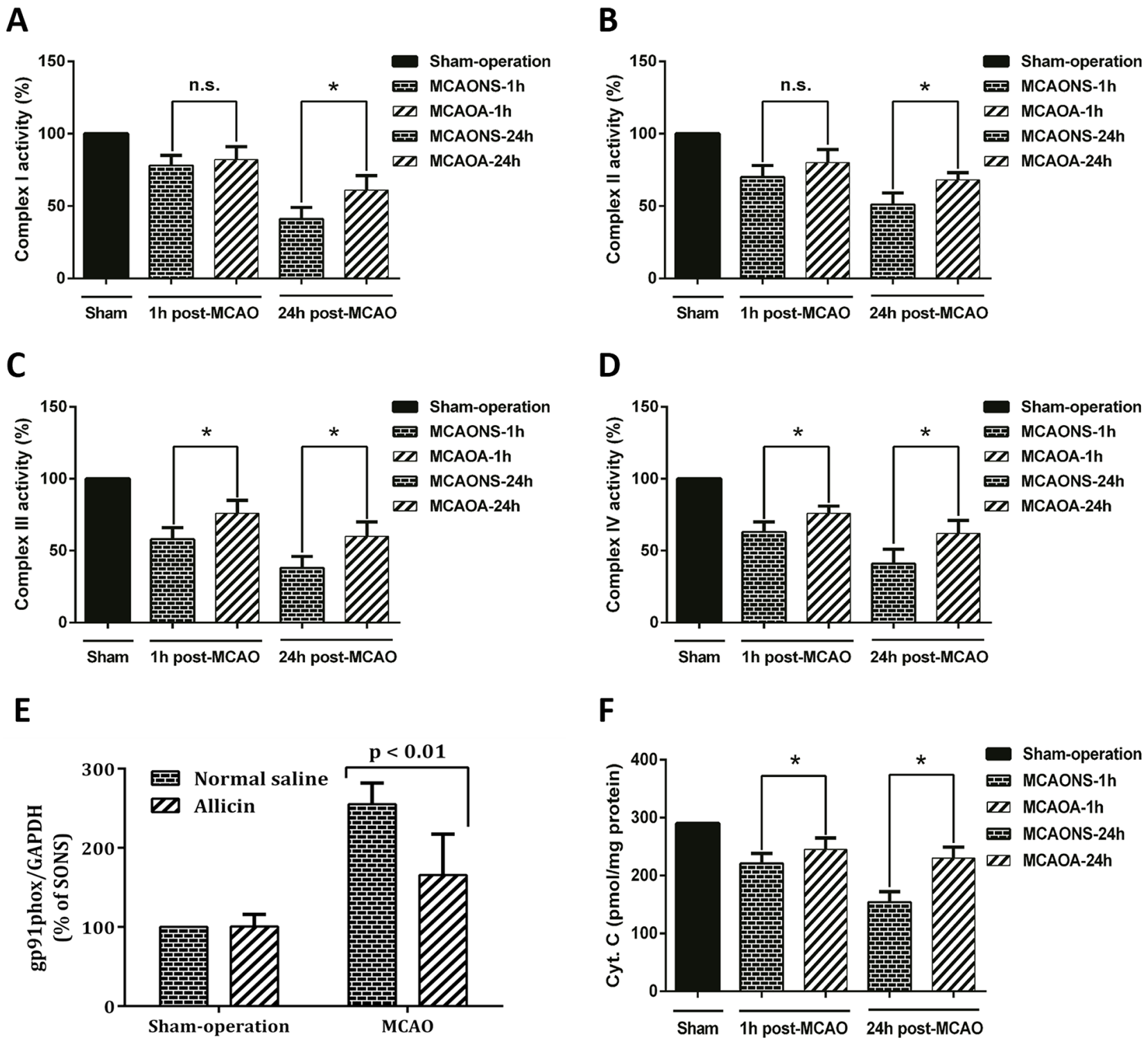

Figure 8: Allicin improved mitochondrial respiratory chain function in MCAOA mice brain. Mitochondria were isolated from the brain tissue of MCAONS mice and MCAOA mice and the activities of mitochondrial respiratory chain complex I (A), complex II (B), complex III (C), and complex IV (D) were detected at 1 and $24 \mathrm{~h}$ after reperfusion. Gp91phox expression was significantly increased in the brains of MCAONS mice compared with that of SONS mice (E), this increase was not observed in the brain of MCAOA mice compared with that of SOA ones (F). The data was represented as means \pm S.E.M. ${ }^{*}$ p $<0.05$; n.s., not statistically significant. 
increased after reperfusion in MCAONS mice brains, the increase was not observed in MCAOA mice, suggesting that Allicin can suppress gp91phox. However, the exact mechanisms underlying the inhibiting effects of Allicin on NADPH oxidase and the involved pathways deserve further investigations.

In this study, the results of brain MRI, neurological deficit assessments, immunohistochemical examinations, western blot and SAFR and MDA tests were consistent with each other. The mechanisms by which Allicin pre-treatment prevented neuron loss might relate to the improvement of blood flow and angiogenesis, the reduction of OS and inflammation, and the repression of apoptosis. All these illustrated the preventative effects of Allicin pre-treatment.

Some limitations exist in our study. Firstly, since Zhang et al. have already explored the effects of Allicin as a post-treatment, we did not totally repeat their intervention methods, but used Allicin as a preventative measure, thus the comparison of the therapeutic effects between preoperative Allicin use and postoperative Allicin use was not performed. Secondly, there are variable neuronal functional recoveries in human patients with ischemic stroke, whether such a standard Allicin administration could also function in human patients needs further research. Thirdly, Allicin, as a molecule predominantly responsible for the antibiotic functions of

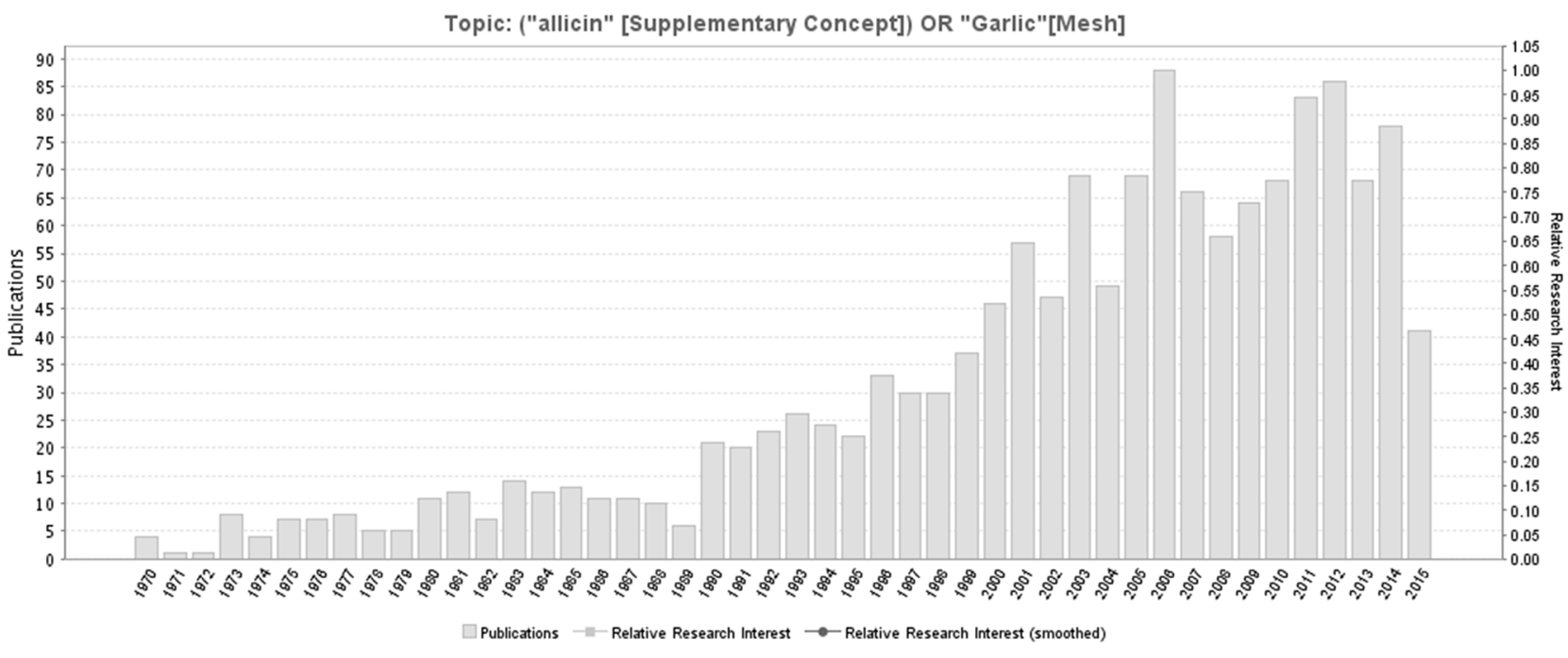

Figure 9: A timeline of the publications related to Allicin.

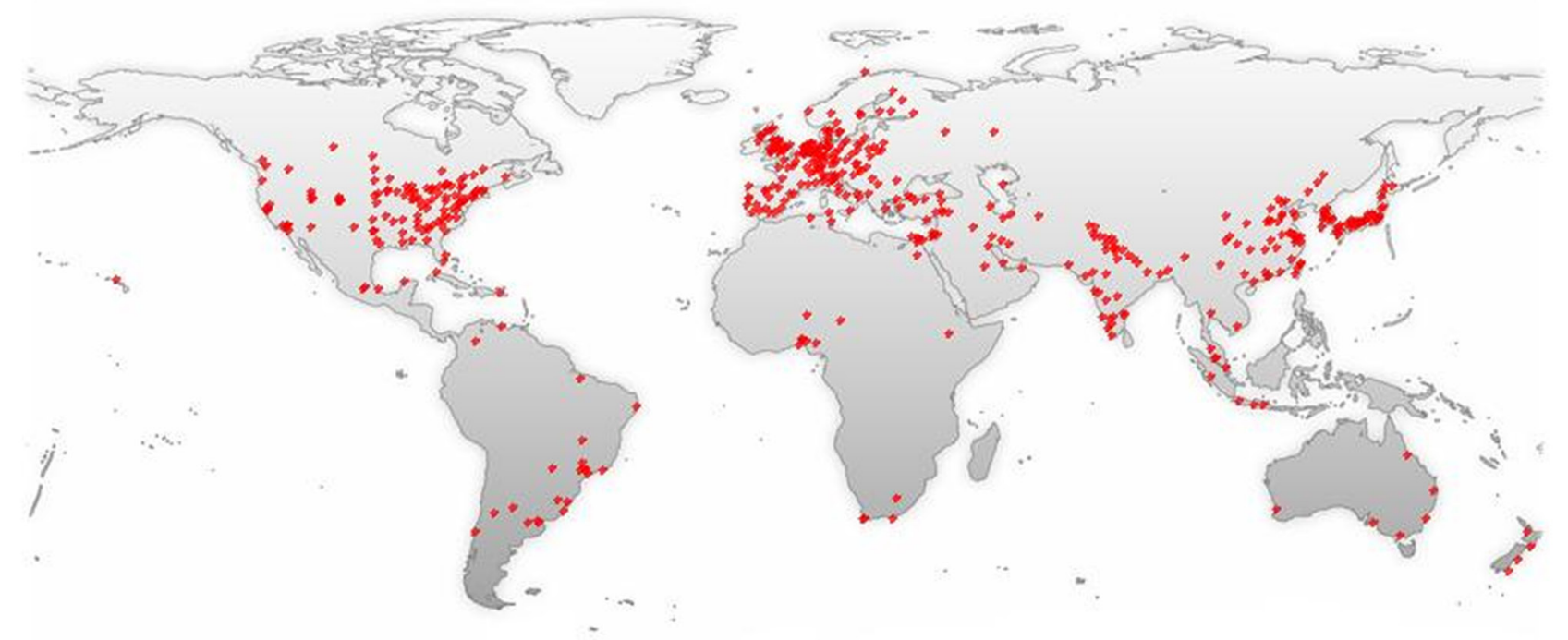

Figure 10: A world map with the global distribution of Allicin -related publications based on the analysis of their geolocational data. 
Table 1: Neurological Severity Scores (NSS)

Evaluation Items

Points

Motor tests

Raising rat by the tail

$-$

1 Flexion of forelimb

1 Flexion of hindlimb

1 Head moved $>10^{\circ}$ to vertical axis within $30 \mathrm{~s}$

Placing rat on the floor (normal=0; maximum=3)

0 Normal walk

1 Inability to walk straight

2 Circling toward the paretic side

3 Fall down to the paretic side

\section{Sensory tests}

1 Placing test (visual and tactile test)

2 Proprioceptive test (deep sensation, pushing the paw against the table edge to stimulate limb muscles)

Beam balance tests $($ normal $=0$; maximum $=6$ )

6

0 Balances with steady posture

1 Grasps side of beam

2 Hugs the beam and one limb falls down from the beam

3 Hugs the beam and two limbs fall down from the beam, or spins on beam $(>60 \mathrm{~s})$

4 Attempts to balance on the beam but falls off (>40 s)

5 Attempts to balance on the beam but falls off $(>20 \mathrm{~s})$

6 Falls off: No attempt to balance or hang on to the beam $(<20 \mathrm{~s})$

\section{Reflexes absent and abnormal movements}

1 Pinna reflex (head shake when touching the auditory meatus)

1 Corneal reflex (eye blink when lightly touching the cornea with cotton)

1 Startle reflex (motor response to a brief noise from snapping a clipboard paper)

1 Seizures, myoclonus, myodystony

Maximum points

18

One point is awarded for the inability to perform the tasks or for the lack of a tested reflex; 13 to 18 indicates severe injury; 7 to 12 , moderate injury; 1 to 6 , mild injury.

garlic, exhibits a variety of pharmacological activities and is beneficial in the treatment of many disorders. Whether there are secondary effects of Allicin on humans remains unclear. Fourthly, in this study, we showed that Allicin administration protects mice from IRBI via a series of molecular biological mechanisms. Nevertheless, most of the effects of Allicin were "attenuating" but not "restoring" (except enzymatic parameters) on the morphometric, histochemical, and biochemical parameters analyzed and compared in MCAONS and MCAOA groups, so more 
mechanism researches on Allicin are necessary in the future. Fifthly, we only studied the effects of Allicin at the dose $50 \mathrm{mg} / \mathrm{kg}$ rather than set a dosage gradient. This is because Zhu et al. has already proved that in Allicin of $50 \mathrm{mg} / \mathrm{kg}$ has better neuroprotective effects on ischemiareperfusion spinal cord injury than $10 \mathrm{mg} / \mathrm{kg}$ and $1 \mathrm{mg} / \mathrm{kg}$; thus, we directly adopted the maximum dose.

\section{MATERIALS AND METHODS}

\section{Animal preparation}

Experiments were performed on 13-15-week-old C57 male mice. Under a dark/light cycle of 12 hours (h), experimental mice were kept at $24^{\circ} \mathrm{C}$ and were fed on water and normal mouse food. Research protocols were approved by the Ethical Committee of Peking Union Medical College Hospital.

\section{MCAO model and hemodynamics monitoring}

As previously described, a transient $\mathrm{MCAO}$ procedure was conducted to induce IRBI on experimental mice. Shamoperated mice underwent the same procedures except without interruption of cerebral blood flow (CBF) in the middle cerebral artery (MCA) [19, 35]. During operation, using laser Doppler flowmetry, we measured the regional $\mathrm{CBF}$ ( $\mathrm{rCBF}$ ) in cortex supplied by MCA. To exclude possible interference on stroke volume by the differences of systemic blood pressure, heart rates and blood pressure were measured according to procedures described by Spescha et al [24]. The experiment was performed blindly.

\section{Experimental grouping design}

Mice were assigned to 4 groups: (a) sham-operated Allicin (SOA) group: pretreated with Allicin $50 \mathrm{mg} / \mathrm{kg}$ by intraperitoneal injection per day for 2 weeks. The same procedures with MACO model making were performed for sham-operated animals. However, the silicone-coated filament was advanced into the internal carotid artery for $5 \mathrm{~mm}$ from the common carotid bifurcation, without interruption of cerebral blood flow in the middle cerebral artery; (b) sham-operated normal saline (SONS) group: the difference between SOA group and SONS group is that mice in SONS group were pretreated with normal saline of the same volume; (c) MCAO Allicin (MCAOA) group: pretreated with Allicin $50 \mathrm{mg} / \mathrm{kg}$ by intraperitoneal injection per day, for 2 weeks, and underwent MCAO procedures; (d) MCAO normal saline (MCAONS) group: pretreated with normal saline of the same volume with MCAOA group, and underwent MCAO procedures. The neuroprotective effects of Allicin were assessed using behavioral and histological techniques as described below. Allicin (purity $>98 \%$ ) was purchased from the National
Institute for the Control of Pharmaceutical and Biological Products (Beijing, China). Allicin was dissolved in 2\% dimethyl sulfoxide (DMSO; Sigma-Aldrich). There were 75 mice in each group. Among the 75 mice, 15 mice were for neurological deficit measurement (1h, 24h, $1 \mathrm{~d}$, and $7 \mathrm{~d}$ ) and the measurements of superoxide anion free radical (SAFR) and malondialdehyde (MDA) in blood (1h and 24h); 15 mice were for MRI scanning and immunohistochemical examinations (24h); 15 mice were for the measurements of anti-oxidant enzymes, NADPH subunit gp91phox, and cytochrome c; and the remaining 30 mice were for the measurements of mitochondrial respiratory chain complexes activities (1h and 24h, 15 mice respectively).

\section{Neurological deficit measurements}

NSS

The neurological severity score (NSS, its brief descriptionis presented as Table 1) evaluation was performed 1 hour, 24 hour, 3 days and 7 days after MCAO blindly [36]. Neural functions were graded as 18 to 0 (maximal deficit score: graded as 18; normal score: graded as 0 ). Neurological deficit measurements were performed by 2 investigators independently and blindly. Number of samples for each group: 15 .

\section{Bederson test}

Using a 4-point scale according to the Bederson test, neurological deficit measurements were also performed at $1 \mathrm{~h}$ and $24 \mathrm{~h}$ after reperfusion as a supplement. The scoring criteria was based on what Bederson described [37]. This test was also conducted by 2 investigators independently in a blinded way. Number of samples for each group: 15.

\section{Measurement of reactive oxygen species and malondialdehyde in blood}

Superoxide anion free radical (SAFR) level can directly reflect the OS degree [38]. Malondialdehyde (MDA) is a bio-marker for lipid-peroxidation [22, 23]. SAFR and MDA production in whole blood was tested using the double antibody Sandwich-Elisa method after $1 \mathrm{~h}$ and $24 \mathrm{~h}$ of reperfusion. Blood was sampled from mouse eyes. We firstly used purified mouse SAFR antibody and MDA antibody to coat microtiter plate wells to make solid-phase antibody, then added SAFR and MDA to wells, respectively. Then the tetramethylbenzidine substrate was added which could become blue under the catalysis of mouse radish peroxidase. Reactions were terminated by adding the sulphuric acid solution which could promote the color to change to yellow. Within a certain extent, the color depth is correlated with the SAFR and MDA content. The optical density (OD) was measured spectrophotometrically at a wave-length of $450 \mathrm{~nm}$. The concentrations of SAFR and MDA in blood were 
determined by comparing the OD of the samples to the standard curve. Number of samples for each group: 15 .

\section{Infarct volume measurement}

After $24 \mathrm{~h}$ of reperfusion, animals were anesthetized using $10 \%$ chloral hydrate and underwent a brain MRI scanning (T2-weighed image, T2WI) by a 3T animal MRI-scanner (Bruker BioSpin MRI PharmaScan) [12, 39]. The mice would be prostrated on a custom-made holder with strapping to minimize head motions. Coronal MRI sections were conducted from $2 \mathrm{~mm}$ anterior to the corpus callosum to the cerebrum end. Parameters: field of view $(\mathrm{FOV})=2.5 \times 2.5 \mathrm{~cm}^{2}$, echo time $(\mathrm{TE})=20 \mathrm{~ms}$, repetition time $(\mathrm{TR})=11189 \mathrm{~ms}$, slice thickness $=1.0$ $\mathrm{mm}$, and matrix size $=128 \times 128$. Volumes of intact zones were measured in cubic millimeters by summing areas and multiplying by the distance between sections blindly. Number of samples for each group: 15 .

\section{Immunohistochemical assessment}

Twenty-four hours after MCAO, mice were anesthetized using $10 \%$ chloral hydrate and perfusionfixed using $4 \%$ paraformaldehyde in PBS $(0.1 \mathrm{~mol} / \mathrm{L})$. The brains were removed rapidly, immersion-fixed in $4 \%$ paraformaldehyde for 4 hours at $4^{\circ} \mathrm{C}$ and cryo-protected using $30 \% \mathrm{PBS} /$ sucrose $\left(72 \mathrm{~h}, 4^{\circ} \mathrm{C}\right)$. The brains were cut into coronal sections (thickness: $30 \mu \mathrm{m}$ ) on a freezing microtome (SM 2000R; Leica, Nussloch, Germany). Sections were incubated with $1.5 \%$ normal blocking serum for $1 \mathrm{~h}$ at normal temperature, and overnight at $4^{\circ} \mathrm{C}$ for immunohistological staining with hematoxylin and eosin and antibodies to neuronal nuclear antigen (NeuN; 1:500; Abcam), 8-hydroxy-2'-deoxyguanosine (8-OHdG; 1:400; GeneTex, San Antonio, TX, USA), Tumor necrosis factor-alpha (TNF- $\alpha ; 1: 500$; Beyotime), CD34 (1:500; Beyotime), Bcl-2 (1:200; Sigma) and Bax (1:200; Sigma). NeuN was used to estimate the numbers of remnant mature neurons in peri-infarct zones [40]. $8-\mathrm{OHdG}$ was used to investigate DNA oxidative damage [21]. TNF- $\alpha$ could reflect the recruitment of inflammatory cells into the brain parenchyma [41]. CD34 reflects the microvessel density and angiogenesis in the ischemic boundary zone [27]. Bax and Bcl-2 were adopted to analyze and compare the degrees of apoptosis [13]. Secondary antibodies and visualization were performed using the ImmPRESS Universal (mouse/rabbit) Ig Kit (Vector Laboratories, Burlingame, CA, USA). The sections were imaged through specific analysis systems (Leica TCSSP2, Leica, Wetzlar, Germany). Immunoreactive cells were counted based on the evaluation of an average of 3 slides from each mouse using ImagePro Plus software (Media Cybernetics, Rockville, MD, USA). The positive cells in the peri-infarct region were counted with a $20 \times$ objective. The areas in each slice only with the densest positive cells would be chosen for counting. Number of samples for each group: 15 .

\section{Measurements of anti-oxidant enzymes activities}

In OS process, various endogenous anti-oxidant enzymes form an anti-oxidant network to protect cells against apoptosis and necrosis [42]. Based on the instructions intechnical manuals of detection-kits (Cayman Chemical, USA), we estimated the activities of anti-oxidant enzymes including glutathione S-transferase (GST, expressed as the percentage of control), superoxide dismutase (SOD, expressed as U/mg protein), glutathione peroxidase (GPX, expressed as the percentage of control) and enzyme activities of catalase (CAT, expressed as U/g protein) in brain homogenates [42]. Number of samples for each group: 15 .

\section{Measurements of mitochondrial respiratory chain complexes activities}

Mitochondrial respiratory chain complex dysfunction has been demonstrated to be one of the most critical influences on IRBI [43]. To elucidate the correlations between Allicin's neuroprotective effects and mitochondrial dysfunction, we firstly measured the activities of complexes I-IV of mitochondrial electron transport chain (ETC) in injured brain tissues. Brain tissues were obtained at 1 or $24 \mathrm{~h}$ after reperfusion, and mitochondria were purified as described earlier [44]. It would take 3 freeze-thaw cycles to disrupt membranes and have enzymes exposed. Four enzymes were selected to be measured at $37^{\circ} \mathrm{C}$ (presented as the percentage of control): NADH dehydrogenase (complex I), succinate dehydrogenase (complex II), ubiquinol cytochrome c reductase (complex III), and cytochrome c oxidase (complex IV) [45]. Number of samples for each group: 30 ( $1 \mathrm{~h}$ and $24 \mathrm{~h}, 15$ mice respectively).

\section{Mitochondrial NADPH production}

NADPH oxidase is a recognized main source for OS in cardia-cerebrovascular diseases. Thus, NADPH oxidase expressions were measured in brain tissue homogenates after $24 \mathrm{~h}$ of MCAO [32]. NADH expressions were estimated through western blot. The homogenate tissues that were analyzed were isolated cerebral hemispheres. Antibodies against gp91phox, the key subunit, were used at 1:500 dilution. The operation steps and the related reagents used are the same with what Spescha et al. decribed [24]. Number of samples for each group: 15.

\section{Measurement of cytochrome c}

Contents of mitochondrial cytochrome c were measured and analyzed according to the steps described by 
Zhu et al. [10]. After $24 \mathrm{~h}$ of MCAO, the brain tissues were supplemented with bovine serum albumin to an ultimate concentration of $25 \mu \mathrm{m}$. The amounts of cytochrome c were calculated based on the integrated chromatographic peak area [46]. Number of samples for each group: 15.

\section{Statistical analysis}

Statistical analyses were performed using two-way ANOVA analysis of variance. $\mathrm{P}<0.05$ was considered to indicate a significant difference. Statistical analysis and charting were performed using the GraphPad Prism software version 6 (GraphPad Software, Inc., La Jolla, CA, USA) and the IBM SPSS 19.0 software package (SPSS, Inc., Chicago, IL, USA).

\section{CONCLUSIONS}

In summary, our findings showed that Allicin administration could significantly reduce stroke size following IRBI. In line with this, MCAOA mice showed a much milder neurological impairment compared with MCAONS. This protective effect is likely to be mediated by a reduced production of free radicals and inflammatory factors, an attenuated apoptosis, a blunted activation NADPH oxidase, and an improvement of antioxidant enzymes, mitochondrial respiratory chain and cytochrome c. As a natural product, garlic is a widespread dietary component with no reported toxicities. Allicin represents unique advantages and may be an effective and novel drug in preventing IRBI in patients with ischemic stroke undergoing thrombolysis of interventional reperfusion therapies. Future studies including larger animal models, longer follow-up as well as clinical experiments should be performed.

\section{Ethical approval}

All applicable international, national, and/or institutional guidelines for the care and use of animals were followed.

\section{Abbreviations}

IRBI = Ischemia-reperfusion brain injury, OS $=$ oxidative stress, $\mathrm{MCAO}=$ middle cerebral artery occlusion, MRI = Magnetic Resonance Imaging, NeuN $=$ neuronal nuclear antigen, $\mathrm{NADPH}=$ nicotinamide adenine dinucleotide phosphate, CAT $=$ catalase, SOD = superoxide dismutase, GPX = glutathione peroxidase, $\mathrm{GST}=$ glutathione $\mathrm{S}$-transferase, $\mathrm{TNF}=$ tumor necrosis factor, $\mathrm{MPO}=$ myeloperoxidase, NSS = neurological severity score, $\mathrm{rCBF}=$ regional cerebral blood flow, $\mathrm{CCA}=$ common carotid artery, $\mathrm{SBP}=$ systolic blood pressure, $\mathrm{DBP}=$ diastolic blood pressure, $\mathrm{NS}=$ no significance, SAFR = superoxide anion free radical, $\mathrm{MDA}=$ malondialdehyde, 8-OHdG = 8-hydroxy-2'- deoxyguanosine, $\mathrm{ETC}=$ mitochondrial electron transport chain, $\operatorname{ROS}=$ reactive oxygen species.

\section{Author contributions}

Xiangyi Kong, Shun Gong, Lijuan Su, Chen Li, and Yanguo Kong put forward the idea, collected data, made the statistical analysis and drafted the paper.

\section{ACKNOWLEDGMENTS}

We would like to thank our colleagues in the Department of Neurosurgery, Peking Union Medical College Hospital, Chinese Academy of Medical Sciences.

\section{CONFLICTS OF INTEREST}

The authors state that there are no conflicts of interest to disclose.

\section{FUNDING (GRANT SUPPORT)}

This study was funded by Peking Union Medical College Youth Research Funds (2016) (Project No. 3332016010; Grant recipient: Xiangyi Kong) and Peking Union Medical College Graduate Student Innovation Fund (2015) (Project No. 2015-1002-02-09; Grant recipient: Xiangyi Kong). The funders had no role in study design, data collection and analysis, decision to publish, or preparation of the manuscript.

\section{REFERENCES}

1. Feigin VL. Stroke epidemiology in the developing world. Lancet. 2005; 365:2160-2161.

2. Allen CL, Bayraktutan U. Oxidative stress and its role in the pathogenesis of ischaemic stroke. Int J Stroke. 2009; 4:461-470.

3. Moskowitz MA, Lo EH, Iadecola C. The science of stroke: mechanisms in search of treatments. Neuron. 2010; 67:181-198.

4. Chen T, Liu W, Chao X, Qu Y, Zhang L, Luo P, Xie K, Huo J, Fei Z. Neuroprotective effect of osthole against oxygen and glucose deprivation in rat cortical neurons: involvement of mitogen-activated protein kinase pathway. Neuroscience. 2011; 183:203-211.

5. Borek C. Antioxidant health effects of aged garlic extract. The Journal of nutrition. 2001; 131:1010S-1015S.

6. Li S, Chen S, Yang W, Liao L, Li S, Li J, Zheng Y, Zhu D. Allicin relaxes isolated mesenteric arteries through activation of PKA-KATP channel in rat. Journal of receptor and signal transduction research. 2017;37:17-24.

7. Corral MJ, Benito-Pena E, Jimenez-Anton MD, Cuevas L, Moreno-Bondi MC, Alunda JM. Allicin Induces Calcium and Mitochondrial Dysregulation Causing Necrotic Death 
in Leishmania. PLoS neglected tropical diseases. 2016; 10:e0004525.

8. Tu G, Zhang YF, Wei W, Li L, Zhang Y, Yang J, Xing Y. Allicin attenuates $\mathrm{H}(2) \mathrm{O}(2)$-induced cytotoxicity in retinal pigmented epithelial cells by regulating the levels of reactive oxygen species. Molecular medicine reports. 2016; 13:2320-2326.

9. El-Sheakh AR, Ghoneim HA, Suddek GM, Ammar ES. Attenuation of oxidative stress, inflammation, and endothelial dysfunction in hypercholesterolemic rabbits by allicin. Canadian journal of physiology and pharmacology. 2015:1-9. [Epub ahead of print].

10. Zhu JW, Chen T, Guan J, Liu WB, Liu J. Neuroprotective effects of allicin on spinal cord ischemia-reperfusion injury via improvement of mitochondrial function in rabbits. Neurochemistry international. 2012; 61:640-648.

11. Zhang B, Li F, Zhao W, Li J, Li Q, Wang W. Protective effects of allicin against ischemic stroke in a rat model of middle cerebral artery occlusion. Mol Med Rep. 2015; 12:3734-3738.

12. Gauvrit JY, Leclerc X, Pernodet M, Oppenheim C, Leys D, Pruvo JP. [Value of MRI in the etiologic diagnosis of cerebral infarction]. J Radiol. 2005; 86:1080-1089. [Article in French].

13. Liu G, Wang T, Wang T, Song J, Zhou Z. Effects of apoptosis-related proteins caspase-3, Bax and Bcl-2 on cerebral ischemia rats. Biomed Rep. 2013; 1:861-867.

14. Kyrylkova K, Kyryachenko S, Leid M, Kioussi C. Detection of apoptosis by TUNEL assay. Methods Mol Biol. 2012; 887:41-47.

15. Liu C, Cao F, Tang QZ, Yan L, Dong YG, Zhu LH, Wang L, Bian ZY, Li H. Allicin protects against cardiac hypertrophy and fibrosis via attenuating reactive oxygen speciesdependent signaling pathways. The Journal of nutritional biochemistry. 2010; 21:1238-1250.

16. Li XH, Li CY, Xiang ZG, Zhong F, Chen ZY, Lu JM. Allicin can reduce neuronal death and ameliorate the spatial memory impairment in Alzheimer's disease models. Neurosciences (Riyadh). 2010; 15:237-243.

17. Gruhlke MC, Portz D, Stitz M, Anwar A, Schneider T, Jacob C, Schlaich NL, Slusarenko AJ. Allicin disrupts the cell's electrochemical potential and induces apoptosis in yeast. Free radical biology \& medicine. 2010; 49:1916-1924.

18. Gonen A, Harats D, Rabinkov A, Miron T, Mirelman D, Wilchek M, Weiner L, Ulman E, Levkovitz H, Ben-Shushan $\mathrm{D}$, Shaish A. The antiatherogenic effect of allicin: possible mode of action. Pathobiology. 2005; 72:325-334.

19. Shahjouei S, Cai PY, Ansari S, Sharififar S, Azari H, Ganji S, Zand R. Middle Cerebral Artery Occlusion Model of Stroke in Rodents: A Step-by-Step Approach. J Vasc Interv Neurol. 2016; 8:1-8.

20. Aleu A, Mellado P, Lichy C, Kohrmann M, Schellinger PD. Hemorrhagic complications after off-label thrombolysis for ischemic stroke. Stroke. 2007; 38:417-422.
21. Zanolin ME, Girardi P, Degan P, Rava M, Olivieri M, Di Gennaro G, Nicolis M, De Marco R. Measurement of a urinary marker (8-hydroxydeoxy-guanosine, 8-OHdG) of DNA oxidative stress in epidemiological surveys: a pilot study. Int J Biol Markers. 2015; 30:e341-345.

22. Smriti K, Pai KM, Ravindranath V, Pentapati KC. Role of salivary malondialdehyde in assessment of oxidative stress among diabetics. J Oral Biol Craniofac Res. 2016; 6:41-44.

23. Kowalczuk K, Stryjecka-Zimmer M. The influence of oxidative stress on the level of malondialdehyde (MDA) in different areas of the rabbit brain. Ann Univ Mariae Curie Sklodowska Med. 2002; 57:160-164.

24. Spescha RD, Shi Y, Wegener S, Keller S, Weber B, Wyss MM, Lauinger N, Tabatabai G, Paneni F, Cosentino F, Hock C, Weller M, Nitsch RM, et al. Deletion of the ageing gene p66(Shc) reduces early stroke size following ischaemia/ reperfusion brain injury. European heart journal. 2013; 34:96-103.

25. Eltzschig HK, Eckle T. Ischemia and reperfusion-from mechanism to translation. Nature medicine. 2011; 17:1391-1401.

26. del Zoppo GJ, Hallenbeck JM. Advances in the vascular pathophysiology of ischemic stroke. Thrombosis research. 2000; 98:73-81.

27. Kong X, Guan J, Ma W, Li Y, Xing B, Yang Y, Wang Y, Gao J, Wei J, Yao Y, Xu Z, Dou W, Lian W, et al. CD34 Over-Expression is Associated With Gliomas' Higher WHO Grade. Medicine. 2016; 95:e2830.

28. Huang Y, Xie K, Li J, Xu N, Gong G, Wang G, Yu Y, Dong $\mathrm{H}$, Xiong L. Beneficial effects of hydrogen gas against spinal cord ischemia-reperfusion injury in rabbits. Brain research. 2011; 1378:125-136.

29. Girard A, Madani S, Boukortt F, Cherkaoui-Malki M, Belleville J, Prost J. Fructose-enriched diet modifies antioxidant status and lipid metabolism in spontaneously hypertensive rats. Nutrition. 2006; 22:758-766.

30. Henze K, Martin W. Evolutionary biology: essence of mitochondria. Nature. 2003; 426:127-128.

31. Niatsetskaya ZV, Sosunov SA, Matsiukevich D, UtkinaSosunova IV, Ratner VI, Starkov AA, Ten VS. The oxygen free radicals originating from mitochondrial complex I contribute to oxidative brain injury following hypoxiaischemia in neonatal mice. The Journal of neuroscience. 2012; 32:3235-3244.

32. Matsumoto T, Kobayashi T, Wachi H, Seyama Y, Kamata K. Vascular $\mathrm{NAD}(\mathrm{P}) \mathrm{H}$ oxidase mediates endothelial dysfunction in basilar arteries from Otsuka Long-Evans Tokushima Fatty (OLETF) rats. Atherosclerosis. 2007; 192:15-24.

33. Vallet P, Charnay Y, Steger K, Ogier-Denis E, Kovari E, Herrmann F, Michel JP, Szanto I. Neuronal expression of the NADPH oxidase NOX4, and its regulation in mouse experimental brain ischemia. Neuroscience. 2005; 132:233-238. 
34. Liu H, Wei X, Chen L, Liu X, Li S, Liu X, Zhang X. Tetramethylpyrazine analogue $\mathrm{CXC} 195$ protects against cerebral ischemia/reperfusion injury in the rat by an antioxidant action via inhibition of NADPH oxidase and iNOS expression. Pharmacology. 2013; 92:198-206.

35. Hattori K, Lee H, Hurn PD, Crain BJ, Traystman RJ, DeVries AC. Cognitive deficits after focal cerebral ischemia in mice. Stroke. 2000; 31:1939-1944.

36. Chen J, Li Y, Wang L, Zhang Z, Lu D, Lu M, Chopp M. Therapeutic benefit of intravenous administration of bone marrow stromal cells after cerebral ischemia in rats. Stroke. 2001; 32:1005-1011.

37. Bederson JB, Pitts LH, Tsuji M, Nishimura MC, Davis RL, Bartkowski H. Rat middle cerebral artery occlusion: evaluation of the model and development of a neurologic examination. Stroke. 1986; 17:472-476.

38. Manchope MF, Calixto-Campos C, Coelho-Silva L, Zarpelon AC, Pinho-Ribeiro FA, Georgetti SR, Baracat MM, Casagrande R, Verri WA Jr. Naringenin Inhibits Superoxide Anion-Induced Inflammatory Pain: Role of Oxidative Stress, Cytokines, Nrf-2 and the NO-cGMPPKG-KATP Channel Signaling Pathway. PloS One. 2016; 11:e0153015.

39. Pillai DR, Dittmar MS, Baldaranov D, Heidemann RM, Henning EC, Schuierer G, Bogdahn U, Schlachetzki F. Cerebral ischemia-reperfusion injury in rats--a 3 T MRI study on biphasic blood-brain barrier opening and the dynamics of edema formation. J Cereb Blood Flow Metab. 2009; 29:1846-1855.

40. Liu F, Schafer DP, McCullough LD. TTC, fluoro-Jade B and NeuN staining confirm evolving phases of infarction induced by middle cerebral artery occlusion. J Neurosci Methods. 2009; 179:1-8.

41. Liu N, Chen R, Du H, Wang J, Zhang Y, Wen J. Expression of IL-10 and TNF-alpha in rats with cerebral infarction after transplantation with mesenchymal stem cells. Cellular \& molecular immunology. 2009; 6:207-213.

42. Shim SY, Kim HS. Oxidative stress and the antioxidant enzyme system in the developing brain. Korean J Pediatr. 2013; 56:107-111.

43. Wolff V, Schlagowski AI, Rouyer O, Charles AL, Singh F, Auger C, Schini-Kerth V, Marescaux C, Raul JS, Zoll J, Geny B. Tetrahydrocannabinol induces brain mitochondrial respiratory chain dysfunction and increases oxidative stress: a potential mechanism involved in cannabis-related stroke. BioMed research international. 2015; 2015:323706.

44. Sims NR. Rapid isolation of metabolically active mitochondria from rat brain and subregions using Percoll density gradient centrifugation. Journal of neurochemistry. 1990; 55:698-707.

45. Dave KR, DeFazio RA, Raval AP, Torraco A, Saul I, Barrientos A, Perez-Pinzon MA. Ischemic preconditioning targets the respiration of synaptic mitochondria via protein kinase C epsilon. The Journal of neuroscience. 2008; 28:4172-4182.

46. Petrosillo G, Di Venosa N, Moro N, Colantuono G, Paradies V, Tiravanti E, Federici A, Ruggiero FM, Paradies G. in vivo hyperoxic preconditioning protects against rat-heart ischemia/reperfusion injury by inhibiting mitochondrial permeability transition pore opening and cytochrome c release. Free radical biology \& medicine. $2011 ; 50: 477-483$. 